\title{
Correlation between antibutyrylcholinesterasic and antioxidant activities of three aqueous extracts from Tunisian Rhus pentaphyllum
}

\author{
Hedi Ben Mansour ${ }^{1 *}$, Sonia Yatouji ${ }^{2}$, Sihem Mbarek¹, Ikram Houas ${ }^{1}$, Afef Delai $^{1}$ and Dorra Dridi ${ }^{1}$
}

\begin{abstract}
For centuries, plants have been used in traditional medicines and there has been recent interest in the chemopreventive properties of compounds derived from plants. In the present study, we investigated the antibutyrylcholinestrasic (anti-BuChE) and antioxidant (against some free radicals) activities of extracts from Rhus pentaphyllum. Aqueous extracts were prepared from powdered R. pentaphyllum roots, leaves and seeds and characterized for the presence of tannins, flavonoids and coumarins. Seeds aqueous extract contained the highest quantities of both flavonoids and tannins (21.12\% and $17.45 \%$ respectively). In the same way, seeds extracts displayed remarkable inhibition against BuChE over $95 \%$, at $100 \mu \mathrm{g} / \mathrm{ml}$ and with $\mathrm{IC}_{50} 0.74 \mu \mathrm{g} / \mathrm{ml}$. In addition, compared to leaves and roots extracts, seeds aqueous extract revealed relatively strong antiradical activity towards the ABTS.+ $\left(I C_{50}=0.25 \mu \mathrm{g} / \mathrm{ml}\right)$ and DPPH $\left(I C_{50}=2.71 \mu \mathrm{g} / \mathrm{ml}\right)$ free radicals and decreased significantly the reactive oxygen species such $\mathrm{O}_{2}{ }^{-}\left(\mathrm{IC}_{50}=2.9 \mathrm{\mu g} / \mathrm{ml}\right)$ formation evaluated by the non-enzymatic generating $\mathrm{O}_{2}{ }^{-}$system (Nitroblue tetrazolium/riboflavine). These data suggest that the anti-BuChE activities mechanism of these extracts occurs through a free radical scavenging capacities.

The present study indicates that extracts of Rhus pentaphyllum leaves, seeds and roots are a significant source of compounds, such as tannins, flavonoids and coumarins, with anti-BuChE and antioxidant activities, and thus may be useful for chemoprevention.
\end{abstract}

Keywords: Rhus pentaphyllum, anti-Butyrylcholinesterasic activity, free radical scavenging activity, antioxidant activity

\section{Introduction}

Alzheimer's disease (AD) is a degenerative neurological disorder characterized by senile plaques containing amyloid $\beta$ protein and loss of cholinergic neuromediators in the brain $[1,2]$. The most remarkable biochemical change in AD patients is a reduction of acetylcholine (ACh) levels in the hippocampus and cortex of the brain [3]. Therefore, inhibition of acetylcholinesterase (AChE), the enzyme responsible for hydrolysis of $\mathrm{ACh}$ at the cholinergic synapse, is currently the most established approach to treating $\mathrm{AD}$ [4]. While $\mathrm{AChE}$ is found in all excitable tissue, whether nerve or muscle, in most erythrocytes and in placental tissue, $\mathrm{BChE}$ is present more

\footnotetext{
* Correspondence: hedi.mansour@hotmail.fr

'Institut Supérieur de Biotechnologie (ISB), Technopole Sidi Thabet,

Université la Manouba 2020 Ariana Tunisie

Full list of author information is available at the end of the article
}

commonly in the body including the central and peripheral nervous system, liver and plasma [5]. On the other hand, oxidative stress caused by reactive oxygen species (ROS), is known to cause the oxidation of biomolecules leading to cellular damage. It is also speculated to be pathologically important in various neurodegenerative processes including cognitive deficits that occur during normal cerebral aging, Alzheimer's disease (AD) and Parkinson's disease [6-8]. Nowadays, the most accepted theory about the disturbing effect of free radicals in the process of aging was reported by Harman [9]. Later on, it was also reported that oxidative stress is associated with the pathogenesis of $\mathrm{AD}$ and cellular characteristics of this disease are either causes or effects of oxidative stress $[10,11]$.

These evidences clearly show that oxidative stress, an early event in $\mathrm{AD}$, may play a key pathogenic role in the

\section{C) Biomed Central}


disease [12]. Interestingly, intake of polyphenols through diets rich in fruits, vegetables and beverages such as red wine was stated to reduce incidence of certain age related neurological disorders including macular degeneration and dementia $[6,13]$. Therefore, the supplemental consumption of polyphenolic antioxidants compounds by people could reduce the risk of AD.

Recently, plant extracts have been the subject of a lot of research in order to obtain compounds able to inhibit AChE. Most of these studies indicate that plants are a good source of molecules with this inhibition activity $[14,15]$. Most of the compounds isolated from the plant polar extract fraction are polyphenols $[16,17]$. These compounds also have a high antioxidant activity $[16,18]$. The antioxidant activity found in some compounds has been connected to the capacity to scavenge the free radicals that are formed during the inflammation processes [19].

As part of our studies on potential chemopreventive agents, we have evaluated the antibutyrylcholinesterasic, antiradical, and antioxidant effects of aqueous extracts from Rhus pentaphyllum collected from Melloulech in the center of Tunisia.

\section{Materials and methods}

\subsection{Chemicals}

1,1-diphenyl-2-picryl-hydrazyl (DPPH), allopurinol, $\alpha$ tocopherol, nitroblue- tetrazolium (NBT), 6-hydroxy2,5,7,8-tetramethylchroman-2-carboxylic acid (Trolox), 2,2'-azino-bis(3-ethylbenzothiazoline-6-sulfonic acid) diammonium salt $\left(\right.$ ABTS $^{++}$) were obtained from Sigma Co (St. Louis, USA). Butyrylthiocholine iodide and 5,5'dithiobis [2-nitrobenzoic acid] (DTNB) were purchased from Quimica Clinica Aplicada S.A. (Amposta, Spain).

\subsection{Plant materials}

R. pentaphyllum was collected from station of Melloulech situated in the Center east of Tunisia in December 2008. Botanical identification was carried out by Dr. Amer Aissi (Pharmacognosy laboratory Faculty of Pharmacy Monastir - Tunisia). A voucher specimen (RP10.03) has been deposited in the High Biotechnological Institute Sidi Thabet, for future reference.

\subsection{Extraction Procedure}

Three aqueous extracts were prepared from respectively the powdered leaves, root and seeds by boiling in water for $1 \mathrm{~h}$. The extracts were filtered and lyophilized, and the residues were dissolved in water.

\subsection{Preliminary phytochemical analysis}

The various aqueous extracts were screened for the presence of tannins and flavonoids by using the methods previously described by Mansour et al. [20] Two milligrams of each extract were dissolved in $2 \mathrm{ml}$ of water. The identification of major chemical groups was carried out by thin layer chromatography (TLC) on silica gel 60 F254 Merck (layer thickness, $0.25 \mathrm{~mm}$ ), as follows. For flavonoids, the TLC was developed in nbutanol/acetic acid/water (4:1:5), and the spots were visualized with $1 \%$ aluminium chloride in methanol under UV (366 nm). The test for tannins was carried out with $\mathrm{FeCl}_{3}$. Each class of tannins produced a specific color.

\subsection{Quantitative analysis of extracts}

Flavonoids were quantified by using the method described by Dohou et-al [21]. Twenty milligrams of each extract were dissolved separately in $2 \mathrm{ml}$ of $80 \%$ methanol and sonicated (30 sec, 100\%) with a Sonics vibra-cell ultrasonic processor (Bioblock Scientific, Illkirch, France). After addition of $100 \mu \mathrm{l}$ of diphenylborinic acid 2-aminoethyl ester (1\% (w/v) in methanol) to each solution, the absorbance of flavonoids was determined spectrophotometrically at $404 \mathrm{~nm}$ and compared to a quercetin standard $(0.05 \mathrm{mg} / \mathrm{ml})$. The percentage of total flavonoids was then calculated in quercetin equivalents according to the following formula:

$$
F=\left(0.05 A_{\text {ext }} / A_{q}\right) 100 / C_{\text {ext }}
$$

where Aext and Aq were the absorbance of the extract and of quercetin, respectively, and Cext was the extract concentration $(10 \mathrm{mg} / \mathrm{ml})$.

Tannins were quantified according to the method developed by Porter et al. [22] and adapted by Mansour et al. [20]. Solutions $(1 \mathrm{~g} / \mathrm{l})$ of each extract were sonicated (30 sec, 100\%), distributed in glass tubes, and sealed with a Teflon-lined screw cap. $2.5 \mathrm{ml}$ of n-butanol- $\mathrm{HCl}(95: 5, \mathrm{v} / \mathrm{v})$ and $100 \mu \mathrm{l}$ of a $2 \%(\mathrm{w} / \mathrm{v})$ ferric reagent $\left(\mathrm{NH}_{4} \mathrm{Fe}\left(\mathrm{SO}_{4}\right)_{2}, 12 \mathrm{H}_{2} \mathrm{O}\right)$ were added to each tube. The solutions were capped, thoroughly mixed, and suspended in a constant-level water bath at $95^{\circ} \mathrm{C}$ for 40 min. The solutions were cooled and the visible spectrum was determined at $540 \mathrm{~nm}$. The percentage of total condensed tannins was then calculated in cyanidol (standard) equivalents according to the following formula:

$$
\mathrm{T}=\left[\left(\mathrm{A}_{540 \mathrm{~nm}} / \in \mathrm{l}\right) 1 / \mathrm{C}_{\text {ext }}\right] 100
$$

Where $\mathrm{l}=1 \mathrm{~cm}, \epsilon=42390 \mathrm{l} / \mathrm{mol} / \mathrm{cm}$, and $C_{\text {ext }}$ is extract concentration.

\subsection{In vitro Butyrylcholinesterase inhibition assay Human plasma preparation}

Human blood from anonymous healthy men subject (27 years) was provided by the Centre d'Assistance Médical Urgente (C.A.M.U) Hôpital Charles Nicolle in Tunisia. Blood was collected in EDTA treated $(1 \mathrm{mg} / \mathrm{ml})$ glass 
tubes, the red blood cells were eliminated by centrifugation at $2000 \mathrm{~g}$ for $10 \mathrm{~min}$, the plasma (supernatant) was then recuperated and diluted (1/200) with $50 \mathrm{mM}$ phosphate buffer $(\mathrm{pH}=7.4)$. Plasma was used immediately for studying butyrylcholinesterase (BuChE) activity or conserved at $2-8^{\circ} \mathrm{C}$ (stable for 7 days).

\section{Butyrylcholinesterase inhibition assay}

BuChE inhibiting activity was measured by the spectrophotometric method previously reported by Ellman et al. [23], modified by Ortega et al. [24] and adapted according to our experimental conditions. Butyrylthiocholine iodide was used as substrate to assay butyrylcholinesterase activity. In order to calculate the activity of the obtained butyrylcholinesterase, the following procedure was employed: $1.5 \mathrm{ml}$ of phosphate buffer $50 \mathrm{mM}$ $\mathrm{pH}=7.2$, containing $0.26 \mathrm{mM}$ of $5,5^{\prime}$-dithiobis-2- nitrobenzoic acid (DTNB), $10 \mu \mathrm{l}$ of human plasma and $10 \mu \mathrm{l}$ of the tested compound $(1,10$ and $100 \mu \mathrm{g} / \mathrm{ml}$ as final concentrations) were placed in a microcuvette, which was incubated for $15 \mathrm{~min}$ at $30^{\circ} \mathrm{C}$. The hydrolysis of butyrylthiocholine was monitored by the formation of yellow 5-thio-2-nitrobenzoate anions resulting from the reaction of DTNB with the thiocholine released by the enzymatic hydrolysis of butyrylthiocholine. Absorbance was measured using an M350 double Beam UV-VIS spectrophotometer «Camespec» at $405 \mathrm{~nm}$, and the reading was repeated during $75 \mathrm{~s}$ at intervals of $30 \mathrm{~s}$ to verify the linearity of the reaction. The enzymatic activity was calculated using the absorption coefficient 23460 and according to the relation:

Enzymatic activity $(\mathrm{UI} / 1)=23460 \times\left(\mathrm{DO}_{405 \mathrm{~nm}} \mathrm{t}_{0 \mathrm{~s}}-\mathrm{DO}_{405 \mathrm{~nm}} \mathrm{t}_{75 \mathrm{~s}}\right)$

The percentage (\%) inhibition of BuChE activity was calculated as follows $(E-S) / E \times 100$, where $E$ is the activity of the enzyme without test compound (in our case $\mathrm{E}=9000 \mathrm{UI} / \mathrm{l}$ (international unite)) and $\mathrm{S}$ is the activity of enzyme with test compound.

$\mathrm{IC}_{50}$ (concentrations of test compounds that inhibited the hydrolysis of substrate (butyrylthiocholine) by 50\%) values were calculated from dose-inhibition curves [25]. All experiments were repeated three times.

\subsection{DPPH radical-scavenging activity}

The free-radical scavenging capacity of the extracts was determined with DPPH [26]. Ethanol solutions were prepared containing $100,30,10,3$ and $1 \mu \mathrm{g} / \mathrm{mL}$ of the extracts and $23.6 \mu \mathrm{g} / \mathrm{ml}$ of DPPH. After incubation for $30 \mathrm{~min}$ at ambiant temperature, the absorbance of the remaining DPPH was determined colorimetrically at 517 $\mathrm{nm}$. Radical scavenging activity was measured as the decrease in absorbance of the samples versus a DPPH standard solution [27]. Results were expressed as "percentage inhibition"(\%) of the DPPH and the mean 50\% inhibiting concentration $\left(\mathrm{IC}_{50}\right) . \%$ is defined by the formula:

$$
(\%)=\left[\left(\mathrm{OD}_{\text {control }}-\mathrm{OD}_{\text {sample }}\right) / \mathrm{OD}_{\text {control }}\right] \times 100,
$$

Where $\mathrm{OD}_{\text {control }}$ is the initial absorbance and $\mathrm{OD}_{\text {sample }}$ the value for the test sample after incubation [27]. $\mathrm{IC}_{50}$ was defined as the concentration (in $\mu \mathrm{g} / \mathrm{ml}$ ) of substrate that causes $50 \%$ loss of DPPH activity (color) and it was calculated by using the Litchfield and Wilcoxon test [20].

The results are expressed as the mean of data from at least three independent experiments.

\subsection{Radical-scavenging activity on $\mathrm{ABTS}^{+}$}

An improved ABTS $^{+}$(2,2'-azino-bis (3-ethylbenzthiazoline-6-sulfonic acid) diammonium salt) radical cation decolorization assay was used [28]. It involves the direct production of the blue/green $\mathrm{ABTS}^{+}$. chromophore through the reaction between $\mathrm{ABTS}^{\cdot+}$ and potassium persulfate. Addition of antioxidants to the preformed radical cation reduces it to $\mathrm{ABTS}^{+}$, to an extent and on a timescale depending on the antioxidant activity, the concentration of the antioxidant and the duration of the reaction [29]. $\mathrm{ABTS}^{+}$was dissolved in water to a $7 \mathrm{mM}$ concentration. $\mathrm{ABTS}^{+\cdot}$ was produced by reacting $\mathrm{ABTS}^{+}$ stock solution with $2.45 \mathrm{mM}$ potassium persulfate (final concentration) and allowing the mixture to stand in the dark at room temperature for 12-16 h before use. The $\mathrm{ABTS}^{+\cdot}$ solution was diluted with ethanol to an absorbance of $0.7( \pm 0.02)$ at $734 \mathrm{~nm}$. In order to measure the antioxidant activity of extracts, $10 \mu \mathrm{l}$ of each sample at various concentrations $(0.5,2.5,4.5,7.5$ and $9.5 \mathrm{mg} /$ $\mathrm{ml}$ ) was added to $990 \mu \mathrm{l}$ of diluted $\mathrm{ABTS}^{+}$and the absorbance was recorded every $1 \mathrm{~min}$. After $30 \mathrm{~min}$ the kinetic reaction was stopped. Each concentration was analyzed in triplicate. The percentage decrease of absorbance at $734 \mathrm{~nm}$ was calculated for each point and the antioxidant capacity of the test compounds was expressed as percent inhibition (\%). $\mathrm{IC}_{50}$ value (concentration required to reduce $\mathrm{ABTS}^{+\cdot}$ by $50 \%$ ) was calculated from regression analysis. Trolox (6-hydroxy2,5,7,8-tetramethylchroman-2-carboxylic acid) is used as a standard in comparison for the determination of the antioxidant activity of a compound. The results are also reported as the Trolox equivalent antioxidant capacity (TEAC), which is the molar concentration of the Trolox giving the same percentage decrease of absorbance of the $\mathrm{ABTS}^{+\cdot}$ radical cation as $1 \mathrm{mg} / \mathrm{ml}$ of the antioxidant testing extract, at a specific time point [29].

\subsection{Superoxide radical-scavenging activity}

The inhibition of NBT reduction by photochemically generated $\mathrm{O}_{2}{ }^{--}$was used to determine the superoxide 
anion scavenging activity of the extracts [30]. The reaction mixture contained $6.5 \mathrm{mM}$ EDTA, $4 \mu \mathrm{M}$ riboflavin, $96 \mu \mathrm{M}$ NBT, and $51.5 \mathrm{mM}$ potassium phosphate buffer $(\mathrm{pH}$ 7.4). Superoxide anions were measured by the increase in the absorbance at $560 \mathrm{~nm}$ after $6 \mathrm{~min}$ of illumination at room temperature. The plant extracts and the reference substance (Quercetin) were assayed at different concentrations with three repetitions. $\mathrm{IC}_{50}$ values (concentration required to inhibit NBT reduction by $50 \%)$ were calculated from dose-inhibition curves $[31,20]$.

\subsection{Statistical Analysis}

Data were expressed as the mean 6 standard deviation of three independent experiments. The statistical analyses were performed with SPSS ${ }^{\mathrm{TM}}$ software v.10.0 (from SPSS Inc.). Data were analyzed for statistical significance using Dunnett's test.

\section{Results}

\subsection{Phytochemical analysis}

The results of our analysis on the lyophilized aqueous extracts are shown in table 1 and 2 . Seeds aqueous extract contained the highest quantities of both flavonoids and tannins (21.12\% and $17.45 \%$ respectively). The leaves extract had lower amounts of flavonoids and tannins $(12.3 \%$ and $10.31 \%$, respectively). Whereas, compared to the other extracts, the roots aqueous extract contained relatively high quantity of tannins, while flavonoids was not detected in this extract (table 2).

The qualitative phytochemical screening showed that only seeds extract contained coumarins (table 1).

\subsection{In vitro butyrylcholinesterase inhibition effect}

Results of human plasma BuChE inhibitory activity of the tested $R$. pentaphyllum extracts are shown in table IV. All tested extracts were found to inhibit the BuChE activity. The inhibition was instantly, as evidenced by the linearity of the absorbance $v s$. time traces during the $75 \mathrm{~s}$ assay period $\left(r^{2}>0.978\right)$.

Results indicated that $R$. pentaphyllum extracts decreased significantly the human BuChE activity in a concentration-dependent manner (table 3).
Seeds and leaves aqueous extract displayed remarkable inhibition over 50\% (95\% and $87 \%$, respectively) at 100 $\mu \mathrm{g} / \mathrm{ml}$ against $\mathrm{BuChE}$ and with $\mathrm{IC}_{50} 0.74$ and $0.81 \mu \mathrm{g} /$ $\mathrm{ml}$. Roots aqueous extract have somewhat lower inhibitory activity with $\mathrm{IC}_{50}$ value $10.35 \mu \mathrm{g} / \mathrm{ml}$.

\subsection{Antioxidant activities}

Oxidative effect of plant extracts cannot be evaluated by only a single method. Therefore, commonly accepted assays, including enzymatic and nonenzymatic methods, were employed to evaluate oxidative effects of some medicinal plants. Three different reactive species were used to evaluate the antioxidant activity of the $R$. pentaphyllum extracts; the ABTS ${ }^{+}, \mathrm{DPPH}$ and superoxide radicals.

\section{DPPH radical-scavenging activity}

$\mathrm{DPPH}$ is a molecule containing a stable free radical. The presence of antioxidant substances could be revealed by the decrease of the intensity the purple color typical of the free DPPH radical [32]. This simple test can provide information on the ability of a compound to donate an electron, the number of electrons a given molecule can donate, and the mechanism of antioxidant action. The radical-scavenging activities of the extracts measured as decolorizing activity following the trapping of the unpaired electron of DPPH are shown in Table 4.

The seeds and leaves aqueous extracts were very potent radical scavengers, with a percentage decrease versus the absorbance of the DPPH standard solution of 90 and $78 \%$, respectively, at a concentration of $100 \mu \mathrm{g} /$ $\mathrm{ml}$, and $\mathrm{IC}_{50}$ values of 2.71 and $2.91 \mu \mathrm{g} / \mathrm{ml}$. These values were slightly greater than that of the positive control, 3 $\mu \mathrm{g} / \mathrm{ml} \alpha$-tocopherol. Aqueous extract $(100 \mu \mathrm{g} / \mathrm{ml})$ obtained from roots have scavenging activity of $70 \%$ and have $\mathrm{IC}_{50}$ value of $10.10 \mu \mathrm{g} / \mathrm{ml}$.

\section{Radical-Scavenging activity on ABTS ${ }^{+}$}

The free radical scavenging capacity of $R$. pentaphyllum extracts was evaluated by ABTS $^{++}$assay (Table 5). Decolorization of $\mathrm{ABTS}^{++}$reflects the capacity of antioxidant species to donate electrons or hydrogen atoms to inactivate this radical cation. A potential activity was noted at different tested concentrations of all extracts studies (table 3). Tested extracts seem to be more actives than

Table 1 Qualitative phytochemical screening of extracts from Rhus pentaphyllum

\begin{tabular}{cccc}
\hline & Seeds aqueous extract & Leaves aqueous extract & ++ \\
\hline Tannins & ++ & ++++ & ++ \\
\hline Flavonoids & - & - & - \\
\hline Anthraquinones & - & - & - \\
\hline Alkaloids & ++ & - & - \\
\hline Coumarins & - & - \\
\hline Saponosids & +
\end{tabular}

-: not detectable; ++: high quantities, ++++: very high quantities. 
Table 2 Quantitative Phytochemical Screening (\%) of extracts from Rhus pentaphyllum

\begin{tabular}{llll}
\hline & Seed aqueous extract & Leaves aqueous extract & Roots aqueous extract \\
\hline Tannins & $17.45^{*}$ & 10.31 & $35.51^{* *}$ \\
\hline Flavonoids & $21.12^{* *}$ & $12.3^{* *}$ & 0 \\
\hline
\end{tabular}

Significant difference obtained with: ${ }^{*} \mathrm{P}<0.05:{ }^{*} \mathrm{P}<0.01$

The reported comparisons concern the contents of extracts in the flavonoids and tannins.

Trolox (reference), as $\mathrm{IC}_{50}$ value obtained with trolox (0.76) is greater than that obtained with the seeds, and leaves aqueous extracts $(0.25,0.37 \mathrm{mg} / \mathrm{ml})$. Roots aqueous extract have somewhat lower inhibitory activity with $\mathrm{IC}_{50}$ value $2.31 \mathrm{mg} / \mathrm{ml}$.

The TEAC of different extracts was also calculated. The TEAC values reflect the relative ability of hydrogen or electron-donating antioxidant of a sample to scavenge the $\mathrm{ABTS}^{+}$radical cation compared with that of Trolox. The results obtained are summarized in table 5 . When referring to TEAC values, seeds, leaves and roots extracts were potent antioxidant with TEAC values of respectively $2.19,1.54$ and $1.32 \mathrm{mM}$, which largely exceed $1 \mathrm{mM}$, the TEAC value of positive control (Trolox).

\section{Effects on superoxide anion generating systems}

The superoxide radical $\left(\mathrm{O}^{-}\right)$is a highly toxic species that is generated by numerous biological and photochemical reactions. Via the Haber-Weiss reaction, it can generate the hydroxyl radical, which reacts with DNA bases, amino acids, proteins, and polyunsaturated fatty acids, and produces toxic effects. The toxicity of the superoxide radical also could be due to the perhydroxyl intermediate $\left(\mathrm{HO}_{2}\right)$ that reacts with polyunsaturated fatty acids. Finally, superoxide may react with NO to generate peroxynitrite, which is known to be toxic towards DNA, lipids, and proteins. The NBT assay is based on the capacity of the extracts to inhibit the photochemical reduction of nitroblue tetrazolium (NBT) in the presence of riboflavin. Under these conditions, NBT can be unevenly reduced in the presence of the $\mathrm{O}^{-}$ ${ }_{2}$ radical to a tetrazoinyl radical that can dismute to the formazan. In the presence of an antioxidant that can donate an electron to NBT, the purple color typical of the formazan decays, a change that can be followed spectrophotometrically at $560 \mathrm{~nm}$. Results indicated that $R$. pentaphyllum extracts decreased significantly the NBT/riboflavin-generated superoxide radical in a concentration-dependent manner. Seeds aqueous extract seems to be more potent antioxidant with activity percentage of $79 \%$ at the highest concentration $(10 \mathrm{mg} / \mathrm{ml})$ compared to the other test extracts and an $\mathrm{IC}_{50}$ of 2.9 $\mathrm{mg} / \mathrm{ml}$. The seeds aqueous extract was more active than the positive control, quercetin, in the assay (Figure 1). The leaves and roots extracts had somewhat lower inhibitory activity with $\mathrm{IC}_{50}$ values of respectively 4.9 and $9.85 \mathrm{mg} / \mathrm{ml}$.

\section{Discussion}

Principal role of cholinesterase $(\mathrm{ChE})$ is the termination of nerve impulse transmission at the cholinergic synapses by rapid hydrolysis of acetylcholine (ACh).

Table 3 Percentage of inhibitions of butyrylcholinesterase activity by the three aqueous extracts from Rhus pentaphyllum

\begin{tabular}{cccc}
\hline Tested compounds & Concentration $(\boldsymbol{\mu g} / \mathbf{m l})$ & Inhibition (\%) against BuChE & $\begin{array}{c}\text { I } \mathbf{5 0}_{\mathbf{5 0}} \\
(\boldsymbol{\mu g} / \mathbf{m l})\end{array}$ \\
\hline Seeds aqueous extract & 1 & $57.11 \pm 2.00^{*}$ & 0.74 \\
& 10 & $80.34 \pm 2.25^{* *}$ & $94.93 \pm 2.00^{* *}$ \\
\hline Leaves aqueous extract & 100 & $54.78 \pm 1.25^{*}$ & 0.81 \\
& 1 & $76.30 \pm 1.50^{*}$ & 10.35 \\
\hline Roots aqueous extract & 10 & $87.11 \pm 5.50^{*}$ & $32.25 \pm 2.35$ \\
\hline (a) Galanthamine & 100 & $49.01 \pm 3.25$ & $67.81 \pm 3.67^{*}$ \\
\hline
\end{tabular}

Significant difference obtained with: *P $<0.05:{ }^{* *} \mathrm{P}<0.01$

The reported comparisons concern: Seeds aqueous extract versus control ${ }^{(\mathrm{a})}$, leaves aqueous extract versus control $^{(\mathrm{a})}$ and $_{\text {roots }}$ aqueous extract versus control $^{(\mathrm{a})}$. Every concentration is compared with its equivalent in the other extract. 
Table 4 DPPH free-radical scavenging activity of extracts from Rhus pentaphyllum

\begin{tabular}{|c|c|c|c|}
\hline Extracts & $\begin{array}{c}\text { Concentration } \\
(\mu \mathrm{g} / \mathrm{ml})\end{array}$ & $\begin{array}{c}\% \\
\text { Inhibition }\end{array}$ & $\begin{array}{c}I C_{50} \\
(\mu \mathrm{g} / \mathrm{ml})\end{array}$ \\
\hline \multirow[t]{5}{*}{ Seeds aqueous extract } & 1 & $44.34 \pm 2.30^{*}$ & 2.71 \\
\hline & 3 & $53.45 \pm 1.02^{*}$ & \\
\hline & 10 & $66.90 \pm 1.10^{*}$ & \\
\hline & 30 & $80.51 \pm 2.80^{* *}$ & \\
\hline & 100 & $92.12 \pm 2.11^{* *}$ & \\
\hline \multirow[t]{5}{*}{ Leaves aqueous extract } & 1 & $39.45 \pm 0.91$ & 2.91 \\
\hline & 3 & $50.45 \pm 0.75^{*}$ & \\
\hline & 10 & $64.31 \pm 1.50^{*}$ & \\
\hline & 30 & $79.50 \pm 2.80^{*}$ & \\
\hline & 100 & $88.11 \pm 2.55^{* *}$ & \\
\hline \multirow[t]{5}{*}{ Roots aqueous extract } & 1 & $12.12 \pm 0.80$ & 10.10 \\
\hline & 3 & $34.51 \pm 1.35$ & \\
\hline & 10 & $49.51 \pm 2.10$ & \\
\hline & 30 & $63.67 \pm 1.12^{*}$ & \\
\hline & 100 & $70.11 \pm 3.11^{*}$ & \\
\hline \multirow{5}{*}{$\begin{array}{l}\text { (a) } \alpha \text {-Tocopherol } \\
\text { (positive control) }\end{array}$} & 1 & $30 \pm 2.1$ & 3 \\
\hline & 3 & $50 \pm 1.3$ & \\
\hline & 10 & $97.3 \pm 1.8^{* *}$ & \\
\hline & 30 & $98 \pm 1.3^{* *}$ & \\
\hline & 100 & $98.7 \pm 2.2^{* *}$ & \\
\hline
\end{tabular}

Significant difference obtained with: ${ }^{*} \mathrm{P}<0.05:{ }^{*} \mathrm{P}<0.01$,

The reported comparisons concern: Seeds aqueous extract versus roots aqueous extract, leaves aqueous extract versus roots aqueous extract and control $^{(a)}$ versus roots aqueous extract. Every concentration is compared with its equivalent in the other extract.

Inhibition of ChE serves as a strategy for the treatment of Alzheimer's disease (AD), senile dementia, ataxia, myasthenia gravis and Parkinson's disease [33,34] A variety of plants has been reported to show ChE inhibitory activity and so may be relevant to the treatment of neurodegenerative disorders such as AD [15].

In this study, aqueous extracts prepared from leaves, seeds and roots from $R$. pentaphyllum were tested to determine their ability as human BuChE inhibitors. The $\mathrm{BuChE}$ inhibition was determined using an adaptation of the method described by Ellman, et al. [23].

All extracts exhibited moderate to good anti BuChE activity, in fact, the inhibition capacity shows the following order: seeds extract $>$ leaves extract $>$ roots extracts. The best inhibitory activity was exhibited by the seeds extract.

On the other hand, the role of oxidative stress in the pathogenesis of diseases such as macular degeneration, certain types of cancer, and Alzheimer's disease (AD) has received substantial attention. For that reason, we also aimed to look into antioxidant capacities of $R$. pentaphyllum extracts.

Three different reactive species were used to evaluate the antioxidant activity of the $R$. pentaphyllum extracts: the $\mathrm{DPPH}^{-}, \mathrm{ABTS}^{++}$and $\mathrm{O}_{2}{ }^{-}$radicals. The superoxide anion and other ROS contribute to oxidative stress, and are known contributors to genetic damage, as well as degenerative diseases such as cancer [35], Parkinson disease, and heart ischemia [36]. Since, the DPPH And the $\mathrm{ABTS}^{+}{ }^{+}$radicals are not biologically relevant, the DPPH and $\mathrm{ABTS}^{+}$assays were performed as a preliminary study to estimate the direct free-radical scavenging abilities of the test extracts. The activity of extracts against the superoxide radical via the non enzymatic NBT/riboflavin assay system has more relevance to physiological conditions. Results show that, compared to leaves and roots extracts, seeds aqueous extract revealed relatively strong antiradical activity towards the $\mathrm{ABTS}^{++}$and DPPH free radicals and decreased significantly the $\mathrm{O}_{2}{ }^{-}$ formation. Thus, we can suggest that the anti-BuChE activities occurs through free radical scavenging capacities.

The antioxidant and anti-BuChE possibilities of $R$. pentaphyllum extracts are supported by the detection of flavonoids and phenolic compounds. In fact, several flavonoids and other phenolic compounds are considered antioxidants $[37,20]$ and inhibition capacities of BuChE activity $[38,15]$.

It has been reported, oxidative stress, caused by reactive oxygen species (ROS), is known to cause the oxidation of biomolecules leading to cellular damage. It is also speculated to be pathologically important in various neurodegenerative processes including cognitive deficits that occur during normal cerebral aging, Alzheimer's (AD), and Parkinson's diseases [39,40]. Nowadays, the most accepted theory about the disturbing effect of free radicals in the process of aging was reported by Harman [41]. Later on, it was also reported that oxidative stress is associated with the pathogenesis of $\mathrm{AD}$ and cellular characteristics of this disease are either causes or effects of oxidative stress $[42,43]$. These evidences clearly show that oxidative stress, an early event in $\mathrm{AD}$, may play a key pathogenic role in the disease [44]. Thus, we can establish a correlation between the antioxidant and antiBuChE capacities and quantity of these phenolic components. Curiously, the roots aqueous extract contained a high quantity of tannins but it exhibited lowest both antioxidant and anti-BuChE activities than the two other extracts. We cannot, however, exclude the possibility that other compounds, particularly coumarins in the case of seeds aqueous extract, with decreased the $\mathrm{BuChE}$ and free radical properties [45]. On the other hand, it is not necessarily always to be only one compound that is responsible for these effects, which may as well be depend on several compounds that act in a synergistic manner or on compounds which regulate one another. 
Table 5 Concentration-dependent ABTS $^{+}$free radical scavenging activity of Rhus pentaphyllum aqueous extracts and standard antioxidant Trolox

\begin{tabular}{|c|c|c|c|c|}
\hline Extracts & Concentration $(\mathrm{mg} / \mathrm{ml})$ & Inhibition (\%) & TEAC (mM) & $\mathrm{IC}_{50}(\mathrm{mg} / \mathrm{ml})$ \\
\hline \multirow[t]{5}{*}{ Seeds aqueous extract } & 0.5 & $76.4 \pm 3.50^{*}$ & 2.19 & 0.25 \\
\hline & 2.5 & $86.12 \pm 4.25^{* *}$ & & \\
\hline & 4.5 & $98.77 \pm 6.50^{* *}$ & & \\
\hline & 7.5 & $100 \pm 1.00^{* * *}$ & & \\
\hline & 9.5 & $100 \pm 1.50^{* * *}$ & & \\
\hline \multirow[t]{5}{*}{ Leaves aqueous extract } & 0.5 & $61.7 \pm 3.50^{*}$ & 1.54 & 0.37 \\
\hline & 2.5 & $87.8 \pm 4.40^{* *}$ & & \\
\hline & 4.5 & $89 \pm 1.00^{* *}$ & & \\
\hline & 7.5 & $98 \pm 0.50^{* *}$ & & \\
\hline & 9.5 & $100 \pm 2.50^{* * *}$ & & \\
\hline \multirow[t]{5}{*}{ Roots aqueous extract } & 0.5 & $44.1 \pm 0.35$ & 1.32 & 2.31 \\
\hline & 2.5 & $54 \pm 1.10^{*}$ & & \\
\hline & 4.5 & $67.13 \pm 3.10^{*}$ & & \\
\hline & 7.5 & $78.61 \pm 5.10^{*}$ & & \\
\hline & 9.5 & $86.50 \pm 2.35^{* *}$ & & \\
\hline \multirow[t]{5}{*}{ (a) Trolox } & 0.5 & $22.07 \pm 0.25$ & - & 0.76 \\
\hline & 0.625 & $32.21 \pm 0.50$ & & \\
\hline & 0.833 & $53.84 \pm 1.50$ & & \\
\hline & 1.25 & $65 \pm 2.50$ & & \\
\hline & 2.5 & $96.85 \pm 2.80^{* *}$ & & \\
\hline
\end{tabular}

TEAC: Trolox equivalent antioxidant capacity

Significant difference obtained with: ${ }^{*} \mathrm{P}<0.05 ; * * \mathrm{P}<0.01 ; * * * 0.001$

The reported comparisons concern: Seeds aqueous extract versus roots aqueous extract, leaves aqueous extract versus roots aqueous extract and control ${ }^{(a)}$ versus roots aqueous extract. Every concentration is compared with its equivalent in the other extract.

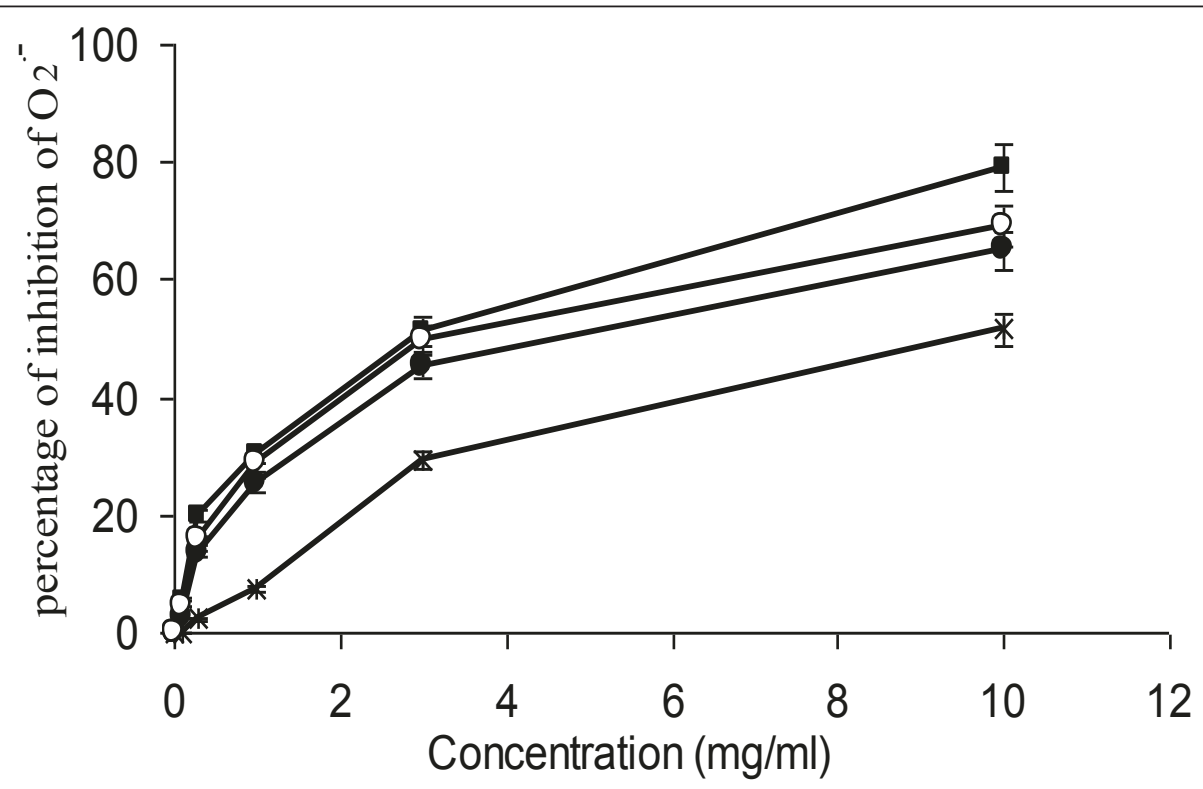

$\rightarrow$ - Seeds aqueous extract
$\rightarrow$ Roots aqueous extract
$\rightarrow-$ Leaves aqueous extract
$\rightarrow-$ Quercetin

Figure 1 Scavenging effects of aqueous extracts of $R$. pentaphyllum against photochemically generated superoxide free radicals $\left(\mathrm{O}_{2}^{-}{ }_{2}\right)$. 
In summary, $R$. pentaphyllum extracts appear to contain compounds with antioxidant and chemoprotective properties. Therefore, these data suggest that high dietary or supplemental consumption of antioxidants in people may reduce the risk of AD. However, further studies are required to fractionate the active extracts, to identify the active compounds, and to determine their exact mechanism of action.

\section{Author details}

${ }^{1}$ Institut Supérieur de Biotechnologie (ISB), Technopole Sidi Thabet, Université la Manouba 2020 Ariana Tunisie. ${ }^{2}$ Unité 05/UR/09-09, Mécanismes Moléculaires et Pathologies, Faculté de Médecine de Monastir, 5019 Monastir, Tunisie.

\section{Authors' contributions}

HBM is the primary author of the manuscript, planed the work, assisted in extracts preparation from powdered R. pentaphyllum roots, leaves and seeds and their chemical characterized. SY contributed in the antibutyrylcholinestrasic activity of all extracts. SM helped in the antioxidant activity against 1,1-diphenyl-2-picryl-hydrazyl (DPPH). AD participated in the antioxidant activity against 2,2'-azino-bis(3-ethylbenzothiazoline-6-sulfonic acid) diammonium salt (ABTS $\left.{ }^{+}\right)$. IH participated in the antioxidant activity against superoxidae anion used by the non-enzymatic system nitrobluetetrazolium (NBT). DD contributed in the statistical analyzes of data. All the authors read and approved the final version of the manuscript.

\section{Competing interests}

The authors declare that they have no competing interests.

Received: 18 June 2011 Accepted: 31 August 2011

Published: 31 August 2011

\section{References}

1. Lawrence AD, Sahakian BJ: The cognitive psychopharmacology of Alzheimer's disease: Focus on cholinergic systems. Neurochem Res 1998,, 23: 787-794.

2. Whitehouse PJ, Price DL, Struble RG, Clark AW, Coyle JT, Delon MR: Alzheimer's disease and senile dementia: Loss of neurons in the basal forebrain. Science 1982, 215: 1237-1239.

3. Jaen JC, Gregor VE, Lee C, Davis R, Emmerling M: Acetylcholinesterase inhibition by fused dihydroquinazoline compounds. Bioorganic Med Chem Lett 1996, 6: 737-742.

4. Schneider LS: New therapeutic approaches to Alzheimer's disease. J Clin Psychiatry 1996, 57:30-36.

5. Massoulie J, Pezzementi L, Bon S, Krejci E, Vallette FM: Molecular and cellular biology of cholinesterases. Prog Neurobiol 1993, 41: 31-91.

6. Bastianetto S, Quirion R: Natural extracts as possible protective agents of brain aging. Neurobiol Aging 2002, , 23: 891-897.

7. Behl C, Moosmann B: Antioxidant neuroprotection in Alzheimer's disease as preventive and therapeutic approach. Free Rad Biol Med 2002, , 33: 182-191.

8. Gray SL, Hanlon JT, Landerman LR, Artz M, Schmader KE, Fillenbaum GG: Is antioxidant use protective of cognitive function in the communitydwelling elderly. Am J Geriatric Pharm 2003, 1:3-8.

9. Harman D: Aging: a theory based on free radical and radiation chemistry. J Gerontol 1956, 11:298-300.

10. Smith MA, Harris PL, Sayre LM, Perry G: Iron accumulation in Alzheimer disease is source of redox-generated free radicals. Proc Nat Acad Sc 1997, 94:9866-9868.

11. Vina J, Lloret A, Orti R, Alonso D: Molecular bases of the treatment of Alzheimer's disease with antioxidants: Prevention of oxidative stress. Mol. Aspect. Med 2004, , 25: 117-123.

12. Zhu X, Raina AK, Lee HG, Casadesus G, Smith MA, Perry G: Oxidative stress signaling in Alzheimer's disease. Brain Res 2004, , 10: 32-39.

13. Commenges D, Scotet V, Renaud S, Jacamin-Gadda H, Barberger-Gateau P, Dartigues JF: Intake of flavonoids and risk of dementia. Eur J Epidemiol 2000, 16: 357-363.
14. Ingkaninan $\mathrm{K}$, Temkitthawon $\mathrm{P}$, Chuenchom K, Yuyaem $\mathrm{T}$, Thongnoi W: Screening for acetylcholinesterase inhibitory activity in plants used in Thai traditional rejuvenating and neurotonic remedies. J Ethnopharmacol 2003, , 89: 261-264.

15. Mukjerjee PK, Kumar V, Mal M, Houghton PJ: Acetylcholinesterase inhibitors from plants. Phytomed 2007, , 14: 289-300

16. Cai Y, Luo Q, Sun M, Corke H: Antioxidant activity and phenolic compounds of 112 traditional Chinese medicinal plants associated with anticancer. Life SC 2004, , 74: 2157-2184.

17. Trouillas P, Calliste CA, Allais DP, Simon A, Marfak A, Delage C, Duroux JL: Antioxidant, anti-inflammatory and antiproliferative properties of sixteen water plant extracts used in Limousin countryside as herbal teas. Food Chem 2003, , 80: 399-407.

18. Djeridane A, Yousfi M, Nadjemi B, Boutassouna D, Stocker P, Vidal N: Antioxidant activity of some Algerian medicinal plants extracts containing phenolic compounds. Food Chem 2006, 97: 654-660.

19. Gomes A, Fernandes E, Lima JLFC, Mira L, Corvo ML: Molecular mechanisms of anti-inflammatory activity mediated flavonoids. Curr Med Chem 2008, , 15: 1586-1605.

20. Mansour HB, Boubaker J, Bouhlel I, Mahmoud A, Bernillon S: Antigenotoxic Activities of Crude Extracts From Acacia salicina Leaves. Environ Mol Mut 2007, , 48: 58-66.

21. Dohou N, Yamni K, Tahrouch S, Hassani Idrissi LM, Badoc A, Gmira N: Screening phytochimique d'une ende'mique ibe'ro-Marocaine, Thymelaea lythoroides. Bull Soc Pharm Bordeaux 2003, 142:61-78.

22. Porter $L$, Hrstich LN, Chan BG: The conversion of procyanidins and prodelphinidins to cyanidin and delphinidin. Phytochemistry 1986, , 25: 223-230

23. Ellman GL, Courtney KD, Andres VJR, Feather-Stone RM: A new and rapid colorimetric determination of acetylcholinesterase activity. Biochem Pharmacol 1961, , 7: 88-95.

24. Ortega MG, Agnese AM, Cabrera JL: Anticholinesterase activity in an alkaloid extract of Huperzia saururus. Phytomed 2004, , 11: 539-543.

25. Noor A-T, Fatima I, Ahmad I, Malik A, Afza N, labal L, Latif M, Khan SB: Leufolins A and B, Potent Butyrylcholinesterase-inhibiting Flavonoid Glucosides from Leucas urticifolia. Molecules 2007, 12:1447-1454.

26. Gülçin I: Antioxidant properties of resveratrol: A structure-activity insight. Innovative. Food Science and Emerging Technologies 2010, 11:210-218.

27. Yagi A, Kabash A, Okamura N, Hararguchi H, Moustafa SM, Khalifa Tl: Antioxidant, free radical scavenging and anti-inflammatory effects of aloesin derivatives in Aloe vera. Planta Med 2002, 68:957-960.

28. Talaz O, Gülçin I, Göksu S, Saracoglu N: Antioxidant activity of 5,10dihydroindeno[1,2-b]indoles containing substituents on dihydroindeno part. Bioorganic and Medicinal Chemistry 2009, 17:6583-6589.

29. Lee SE, Shin HT, Hwang HJ, Kim JH: Antioxidant activity of extracts from Alpinia katsumadai seed. Phytother Res 2003, 17:1041-1047.

30. Gülçin I: Antioxidant activity of L-Adrenaline: An activity-structure insight. Chemico-Biological Interaction; 2009:179:71-80.

31. Re R, Pellegrini N, Proteggente A, Pannala A, Yang M, Rice-Evans C: Antioxidant activity applying an improved $\mathrm{ABTS}^{++}$radical cation decolorization assay. Free Radical Bio Med 1999, 26:1231-1237.

32. Gülçin I, Elias R, Gepdiremen A, Taoubi K, Köksal E: Antioxidant secoiridoids from fringe tree (Chionanthus virginicus L.). Wood Sciences and Technology 2009, 43:195-212.

33. Sokmen M, Angelova M, Krumova E, Pashova S, Ivancheva S, Sokmen A, Serkedjieva A: In vitro antioxidant activity of polyphenol extracts with antiviral properties from Geranium sanguineum L. Life Sci 2005, 76:2981-2993.

34. Atta-ur-Rahman, Choudhary M: Bioactive natural products as a potential source of new pharmacophores a theory of memory. Pure Appl Chem 2001, , 73: 555-560.

35. Sander CS, Chang H, Hamm F, Elsner P, Thiele JJ: Role of oxidative stress and the antioxidant network in cutaneous carcinogenesis. Int J Dermatol 2004, 43: 326-335.

36. Gonzalez-Avila M, Arriaga-Alba M, La-Garza MD, HermandezPreteline MDC, Dominguez-Ortiz MA, Fattel-Fazenda S, Villa-Trevino S: Antigenotoxic, antimutagenic and ROS scavenging activities of a Rhoeo discolor ethanolic crude extract. Toxicol In Vitro 2003, 17:77-83.

37. Cos P, Ying L, Calomme M, Hu JP, Cimanga K, Van Poel B, Potier L, Vlientink AJ, Vanden Berghe D: Structure-activity relationship and 
classification of flavonoids as inhibitors of xanthine oxidase and superoxide scavengers. J Nat Prod 1998, , 61: 71-76.

38. Orhan I, Kartal M, Naz Q, Ejaz A, Yilmaz G, Kan Y, Konuklugil B, Bilge SM, Choudhary I: Antioxidant and anticholinesterase evaluation of selected Turkish Salvia species. Food Chem 2007, , 103: 1247-1254.

39. Bastianetto S, Quirion R: Natural extracts as possible protective agents of brain aging. Neurobiology of Aging 2002, 23:891-897.

40. Behl C, Moosman B: Antioxidant neuroprotection in Alzheimer's disease as preventive and therapeutic approach. Free Radical Biology and Medicine 2002, 33:182-191.

41. Harman D: Aging: a theory based on free radical and radiation chemistry. Journal of Gerontology 1956, 11:298-300.

42. Smith MA, Harris PL, Sayre LM, Perry G: Iron accumulation in Alzheimer disease is source of redox-generated free radicals. Proceedings of National Academy of Sciences of USA 1997, 88:10540-10543.

43. Smith MA, Perry G, Richey PL, Sayre LM, Anderson VE, Beal MF: Oxidative damage in Alzheimer's disease. Nature 1996, 382:120-121.

44. Zhu X, Raina AK, Lee HG, Casadesus G, Smith MA, Perry G: Oxidative stress signaling in Alzheimer's disease. Brain Research 2004, 1000:32-39.

45. Fallarero A, Oinonen P, Gupta S, Blom P, Galkin A, Mohan CG, Vuorela PM: Inhibition of acetylcholinesterase by coumarins: The case of coumarin 106. Pharmacol Res 2008, 58: 215-221.

doi:10.1186/1476-0711-10-32

Cite this article as: Mansour et al: Correlation between

antibutyrylcholinesterasic and antioxidant activities of three aqueous

extracts from Tunisian Rhus pentaphyllum. Annals of Clinical Microbiology and Antimicrobials 2011 10:32.

\section{Submit your next manuscript to BioMed Central} and take full advantage of:

- Convenient online submission

- Thorough peer review

- No space constraints or color figure charges

- Immediate publication on acceptance

- Inclusion in PubMed, CAS, Scopus and Google Scholar

- Research which is freely available for redistribution

Submit your manuscript at www.biomedcentral.com/submit
Biomed Central 